\title{
Article
}

\section{Retrospective Study on Tooth Shell Technique Using Endodontically Treated Teeth in Lateral Ridge Augmentation}

\author{
Michael Korsch ${ }^{1,2,3, *(D)}$ and Marco Peichl ${ }^{1}$ \\ 1 Dental Academy for Continuing Professional Development, Karlsruhe, Lorenzstrasse 7, \\ 76135 Karlsruhe, Germany; marco_peichl@za-karlsruhe.de \\ 2 Clinic of Operative Dentistry, Periodontology and Preventive Dentistry, University Hospital, \\ Saarland University, Building 73, 66421 Homburg, Germany \\ 3 Private Practice, Center for Implantology and Oral Surgery, Berliner Str. 41, 69120 Heidelberg, Germany \\ * Correspondence: michael_korsch@za-karlsruhe.de; Tel.: +49-721-918-1200; Fax: +49-721-918-1222
}

check for updates

Citation: Korsch, M.; Peichl, M. Retrospective Study on Tooth Shell Technique Using Endodontically Treated Teeth in Lateral Ridge Augmentation. Appl. Sci. 2021, 11, 5882. https://doi.org/10.3390/ app11135882

Academic Editor: Gabi Chaushu

Received: 19 May 2021

Accepted: 23 June 2021

Published: 24 June 2021

Publisher's Note: MDPI stays neutral with regard to jurisdictional claims in published maps and institutional affiliations.

Copyright: (c) 2021 by the authors. Licensee MDPI, Basel, Switzerland. This article is an open access article distributed under the terms and conditions of the Creative Commons Attribution (CC BY) license (https:/ / creativecommons.org/licenses/by/ $4.0 /)$.

\begin{abstract}
Autogenous dentin has been reported to be a suitable grafting material for certain indications. The purpose of this study was to assess the feasibility of using endodontically treated teeth for this application. In the present retrospective study, one-stage augmentation of lateral ridge defects with a dentin shell and particulate (tooth shell technique (TST)) either obtained from endodontically treated teeth (ETT, 17 patients with 21 implants) or non-endodontically treated teeth (NETT, 17 patients with 24 implants) were analyzed. Follow-up was conducted 3 months after augmentation. The target parameters were biological complications, horizontal hard tissue loss, osseointegration, and the integrity of the buccal lamella. Only minor complications occurred in three implants from three patients, including two cases of wound dehiscence (one each in ETT and NETT) and a localized three-walled defect in the NETT group, which was solved by re-augmentation. All the implants were osseointegrated and the integrity of the buccal lamella was preserved. The mean difference of the resorption of the crestal width and the buccal lamella did not differ statistically between the two groups. As TST using ETT showed, the results comparable to those of NETT dentin from endodontically treated teeth can be safely applied with predictable results for this grafting technique.
\end{abstract}

Keywords: tooth shell technique; implant; dentin; bone graft; autogenous; endodontically treated teeth

\section{Introduction}

The reconstruction of alveolar crest deficiencies for creating a sufficient implant site is one of the main challenges in oral implantology. Although there are a variety of alloplastic, allogenic, and xenogenic bone substitute materials available for this purpose, grafting procedures using autogenous bone are still considered to be the "gold standard" due to the bone's excellent osteoconductive, osteoinductive, and osteogenic properties [1]. However, a substantial disadvantage is the need for an additional surgical site for graft harvesting, with an increased risk of complications and postoperative comorbidities [2,3].

In recent years, the use of autogenous dentin as a possible alternative autogenous grafting material has become a focus of scientific research [4-6]. Dentin is very similar to the bone in its organic and inorganic composition in terms of percentage and in its individual components. The organic matrix of dentin and bone, for example, consists of $\sim 90 \%$ type I collagen and $\sim 9 \%$ of non-collagenous proteins such as osteocalcin, osteonectin, phosphoproteins, proteoglycans, and sialoprotein, as well as growth factors such as bone morphogenetic proteins, tissue growth factor- $\$$ or insulin-like growth factor-2 [4-7]. Histological analyses have shown that dentin has osteoconductive and osteoinductive properties [6-13] and is involved in the bone remodeling process [14-17]. In addition, autogenous dentin appears to have lower resorption rates than autogenous bone [18,19]. For these reasons, autogenous dentin can be considered as a viable alternative to autogenous bone. 
Meanwhile, the use of dentin has been investigated in numerous implantological measures. These include socket preservation, immediate implant placement, sinus floor elevation, and block transplants $[4,11,13,17,20-22]$.

Since only in very few cases will impacted or retained teeth be available, non-retainable teeth, especially in the area of prospective implant placement, represent the main source of autogenous dentin. While most studies only use uncompromised healthy teeth such as retained or impacted teeth for these indications to minimize the risk of bacterial infection, there is a lack of clinical evidence regarding the use of compromised teeth. Animal studies yielded results that indicate that grafts derived from endodontically treated or periodontally compromised teeth did not show increased signs of inflammation histologically. However, increased graft exposures could be observed compared to grafts obtained from uncompromised teeth $[14,23]$. Teeth that have undergone endodontic treatment, for example, may host residual bacteria in the dentin that were not eliminated by the endodontic procedure. Dentinal tubules represent a niche in which bacteria can persist, even in clinically or radiologically inconspicuous teeth [24]. Residual bacteria in endodontically treated teeth are dominated by anaerobic and Gram-positive microbiota. Recurrent infection after endodontic treatment is mostly characterized by an infection with only one or a few species, while primary endodontic infection is predominantly polymicrobial [25]. One of the most frequently found pathogens in teeth with endodontic failure is Enterococcus faecalis, which is characterized by specific virulence factors, e.g., adhesins [26] and is able to penetrate deeply into the dentinal tubules [27], where they may resist sufficient removal by disinfection procedures during graft preparation. This could be problematic, especially in grafting procedures where sufficient wound closure is desired, such as block grafts.

In the present study, the tooth shell technique (TST) [22] was applied using processed autogenous dentin obtained from endodontically and non-endodontically treated teeth. The tooth shell technique is a modification of the shell technique according to Khoury, in which autogenous bone is used $[28,29]$.

The present retrospective study is a proof-of-concept study. The aim was to determine whether the use of endodontically treated teeth leads to equivalent results compared to teeth that have not been endodontically treated.

\section{Materials and Methods}

For the present study, cases of lateral ridge augmentation were re-examined, in which autogenous dentin from endodontically and non-endodontically treated teeth were used between 1 June 2019 and 31 March 2020. The electronic medical records of the individual patients were used to screen for potential cases for inclusion in this study. All the surgical procedures were performed by an experienced oral surgeon (MK). The study protocol was reviewed and approved by the Institutional Review Board of Baden-Württemberg Medical Council (ID: F-2020-068-z). The study was conducted according to the Declaration of Helsinki and the EQUATOR guidelines. The inclusion criteria for this study considered the following conditions:

Inclusion criteria:

- $\quad$ Age > 18 years;

- Alveolar crest augmentation of a lateral bony defect with the tooth shell technique;

- Lateral alveolar crest defect of at least $4 \mathrm{~mm}$ in the region of implant placement prior to augmentation;

- Restoration with a fixed denture is intended;

- Edentulous region of maximum of two missing teeth.

Exclusion criteria:

- $\quad$ Age $<18$ years;

- Untreated or residual periodontitis;

- Uncontrolled diabetes mellitus with $\mathrm{HbA1c}>7 \%$;

- A malignant neoplasm; 
- A history of therapy with bisphosphonates or other antiresorptive medication (e.g., RANKL inhibitors);

- A history of radiotherapy in the head and neck region;

- Immunosuppression or immunosuppressant therapy;

- A lateral alveolar crest defect of less than $4 \mathrm{~mm}$ in the region of implant placement prior to augmentation;

- The restoration of the implant with a removable denture is intended.

In all patients, either a hopeless tooth or a tooth not worth preserving (such as a wisdom tooth) that would have been suitable for grafting was present in the prospective region of implantation. In all cases, the width of the bucco-palatal bone was measured with preoperative cone beam computed tomography (CBCT) before augmentation. At least $1.5 \mathrm{~mm}$ of bone/autogenous dentin should cover the implants on the buccal and palatal surfaces. The achieved ridge width was a result of the desired implant diameter, a $1.5 \mathrm{~mm}$ buccal and $1.5 \mathrm{~mm}$ oral lamella of original bone or autogenous bone/dentine graft. The desired ridge width was of at least $7.2 \mathrm{~mm}$ when the implant diameter was $4.2 \mathrm{~mm}$. An increase in hard tissue of at least $4 \mathrm{~mm}$ was a requirement for the augmentation procedure in all cases.

The patients were divided into the following two groups: Group 1:

Endodontically treated teeth (ETT): 17 patients (11 female, 6 male) with 18 regions and 21 implants.

Group 2 (control group):

Non-endodontically treated teeth (NETT): 17 patients ( 8 female, 9 male) with 22 regions and 24 implants.

The following data from electronic medical records were extracted for study documentation:

- Demographic data: Age and gender;

- The endodontic status of the tooth used for grafting;

- Data on restoration and maintenance therapy;

- Complications: The loss of the graft or implant, dehiscence, and infections/inflammation;

- Implant data: type, length/diameter, and region;

- After augmentation with simultaneous implantation, a CBCT image was taken to assess the surgical procedure. These $X$-rays were analyzed;

- At the time of implant exposure-3 months after augmentation-CBCT was performed to assess osseointegration, the buccal lamella, and horizontal hard tissue loss. These CBCT images were analyzed.

The target parameters were biological complications, horizontal hard tissue loss, osseointegration, and integrity of the buccal lamella. The biological complications include the following:

Complications concerning the hard and soft tissue:

- The dehiscence of the wound;

- Infection with or without suppuration;

- $\quad$ Severe peri-implant bone loss;

- Implant loss;

- Others.

\subsection{Clinical Complications}

All the complications concerning the graft or the implant during the observation period were documented.

Loss of a graft when the implant surfaces were exposed, either through infection or unexpected massive resorption, and loss of an implant during the follow-up period were defined as severe complications. 
Dehiscence and inflammation/infection of the grafted site were defined as non-severe complications if the implant was fully osseointegrated and no implant surfaces were exposed.

\subsection{Clinical Procedure of the Tooth Preparation}

Following extraction, the tooth intended for augmentation was cleaned mechanically by removing debris, the periodontal ligament, restorations, and root filling material with a coarse diamond bur under water cooling (Figure 1a-d). A thin shell of root dentin ( 1-1.5 mm thickness) was obtained with a rotating diamond disc (Frios MicroSaw, Dentsply Sirona Implants, Mannheim, Germany) under water cooling. The remaining tooth was particulated with a sterile disposable grinder (Smart Dentin Grinder, Kometa Bio, Cresskill, NJ, USA) to 300-1200 $\mu \mathrm{m}$ particles (Figure 1c). For chemical cleaning, defatting and disinfection, the dentin shell and the particulate dentin were placed in a sterile closed dappen dish with a solution of sodium hydroxide $(0.5 \mathrm{~N}, 4 \mathrm{~mL})$ and ethanol $(20 \mathrm{vol} \%, 1 \mathrm{~mL})$ (Dentin Cleanser, Kometa Bio, Cresskill, NJ, USA) for $10 \mathrm{~min}$. After the exposure period, the supernatant was removed with sterile gauze and the material was rinsed by manually shaking in a phosphate-buffered physiological saline solution (Dulbecco's PhosphateBuffered Saline, Kometa Bio, Cresskill, NJ, USA) for 3 min. To expose the collagen fiber network and release osteoinductive growth factors, partial demineralization of the dentin was performed by placing the material in a 10\% EDTA solution for $3 \mathrm{~min}$ (EDTA solution, Kometa Bio, Cresskill, NJ, USA). The material was rinsed again with a buffered saline solution. Then, it was used immediately for grafting or dried at a moderate temperature (below $38^{\circ} \mathrm{C}$ ) on a hotplate and stored in a sterile vessel at $-18^{\circ} \mathrm{C}$ until grafting. At the time of grafting, the grafting material was slightly moistened with saline after thawing. Thawing was performed on the same hotplate that was used before (below $38^{\circ} \mathrm{C}$ ).

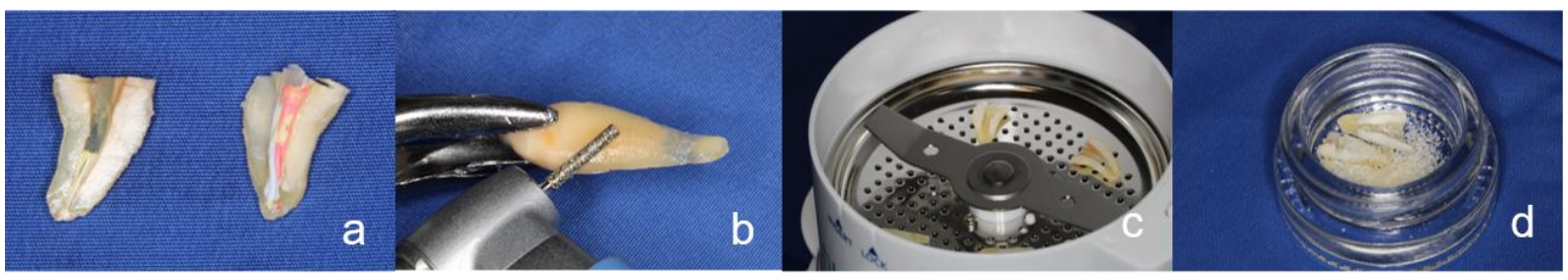

Figure 1. Procedure of the tooth preparation. (a) Endodontically treated tooth split in two halves with a rotating diamond disc. (b) Removal of debris and foreign material, such as restorations and root filling material, as well as the periodontal ligament, from the root surface with a coarse diamond bur under water cooling. (c) Sterile disposable dentin grinder (Smart Dentin Grinder) for particulating the dentin. (d) Dentin particulate and dentin shells.

\subsection{General Surgical Procedure of the Tooth Shell Technique (TST)}

The grafting procedures were performed under perioperative antibiosis (one-day pre- and two days postoperatively) with amoxicillin $750 \mathrm{mg}$ three times per day. In the case of penicillin intolerance, $300 \mathrm{mg}$ Clindamycin was used as a substitute. In addition, $400 \mathrm{mg}$ Ibuprofen was used as an analgesic. All the operations were performed with local anesthetic with Articaine + Epinephrine 1:100,000 (Citocartin Sopira ${ }^{\circledR}$, Heraeus Kulzer $\mathrm{GmbH}$, Hanau, Germany).

The crestal incision of the mucoperiosteal flap with a mesial or distal releasing incision was conducted to access the alveolar crest defect. After flap mobilization and surgical exposure of the alveolar crest, the implant site was prepared according to the protocol of the implant manufacturer. The implants were inserted at the hard tissue level (Figure 2a,b). All the implant surfaces were completely covered by native bone or graft (autogenous dentin) (Figure 2c). The previously obtained and prepared dentin shell was adapted to the alveolar crest defect and fixed with titanium osteosynthesis screws (microscrews ${ }^{\circledR}$, Stoma, Emmingen-Liptingen, Germany). The prepared particulate dentin was placed in the cavity between the tooth shell and implant (Figure 2c). The stability of the fixed dentin shell was checked with dental tweezers. The dentin shell should not have any 
mobility. The mucoperiosteal flap was advanced with a periostal releasing incision to ensure sufficient wound closure without tension. Non-resorbable, monofilament suture material (Supramid ${ }^{\circledR} 5-0$, Serag-Wiessner, Naila, Germany) was used for passive wound closure. For the tooth shell technique, no bone substitute materials or membranes were used. After augmentation with simultaneous implantation (T1), a CBCT image was taken to assess the surgical procedure.

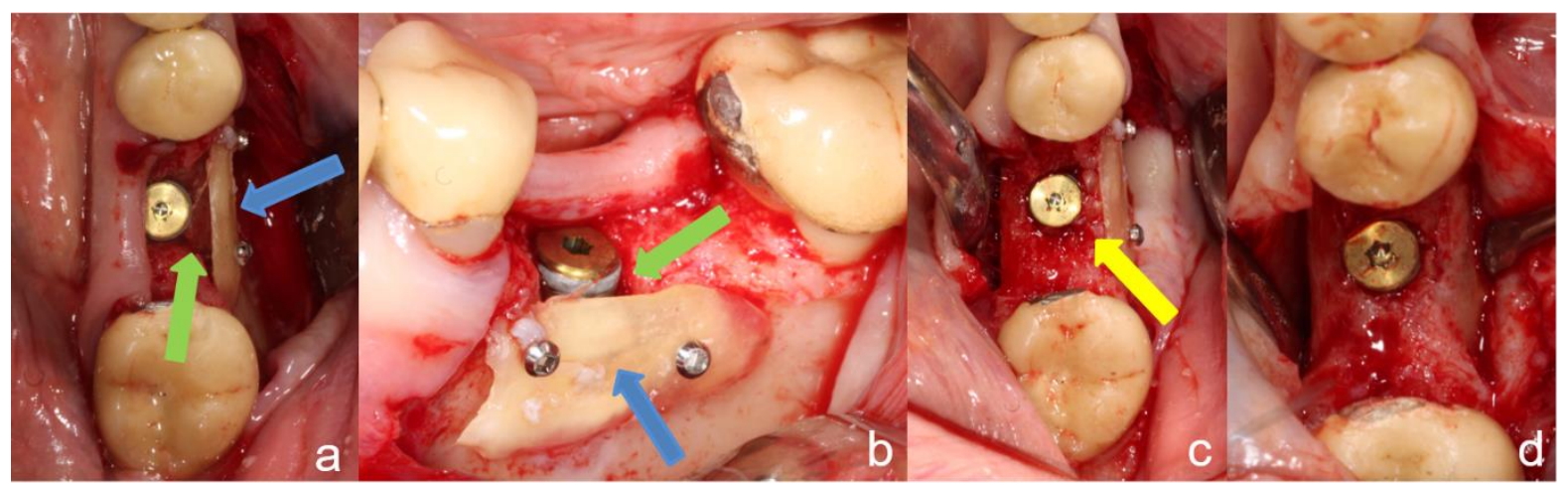

Figure 2. Clinical procedure of the tooth shell technique. $(\mathbf{a}, \mathbf{b})$ Occlusal and lateral view: Inserted implant at the site of tooth 36. The vestibular bone deficit is shown by the green arrows. Dentin shell fixed with osteosynthesis screws to the vestibular aspect of the implant (blue arrows). (c) The hollow space created between the dentin shell and implant was filled with particulate dentin (yellow arrow). (d) Occlusal view at the time of implant exposure with removed osteosynthesis screws. The implant seems to be fully osseointegrated with a stable laterad ridge lateral augmentation.

The implants were exposed 3 months after placement (Figure 2d). The assessment of peri-implant bone level was performed by measuring from the implant shoulder to the bone-implant contact at four locations (mesial, distal, oral, and buccal) with a periodontal probe. The measurement of implant stability was carried out by resonance frequency analysis (Ostell Idx, W\&H, Buermoos, Austria). Only implants with an implant stability quotient (ISQ) of over 60 were approved for prosthetic restoration. CBCT was performed to assess the augmentation and implant success (T2).

\subsection{Radiographic Evaluation}

To evaluate changes in the morphology of the peri-implant hard tissue, especially the buccal lamella of the implants, high-resolution, small-volume CBCT with a $50 \times 50 \mathrm{~mm}$ FOV (PaX-Duo3D, Orange Dental, Biberach an der Riß, Germany) was performed after implant insertion (T1) and at the follow-up 3 months later (T2).

The radiographic evaluation included the assessment of the approximal peri-implant bone level, the thickness and integrity of the buccal lamella, and the crestal width. For evaluation of the approximal peri-implant bone level, the distance between the implant shoulder and the first implant-bone contact was measured at time T2 in a mesiodistally aligned plane as in a 2D radiographic assessment, assuming that the implant was placed at the hard tissue level at T1 (Figure 3a). Only the highest value at the mesial or distal margin was included in the analyses. The integrity of the buccal lamella was assessed in a bucco-palatal aligned plane as shown in Figure $3 \mathrm{~b}$ at time T2. If implant surfaces were detected that were not covered by a radio-opaque structure, the distance between the implant shoulder and the first implant/bone contact was measured (Figure $3 b$ ). The thickness of the buccal lamella was evaluated orthogonally to the implant axis at the level of the implant shoulder (=L0), as well as $2 \mathrm{~mm}(=\mathrm{L} 2)$ and $4 \mathrm{~mm}(=\mathrm{L} 4)$ below the implant shoulder at T1 and T2. The width of the alveolar crest was measured $2 \mathrm{~mm}$ below the implant shoulder in the same plane at T1 and T2. This method of measurement using CBCT of lateral ridge augmentation has been applied in previous studies $[22,30,31]$. 


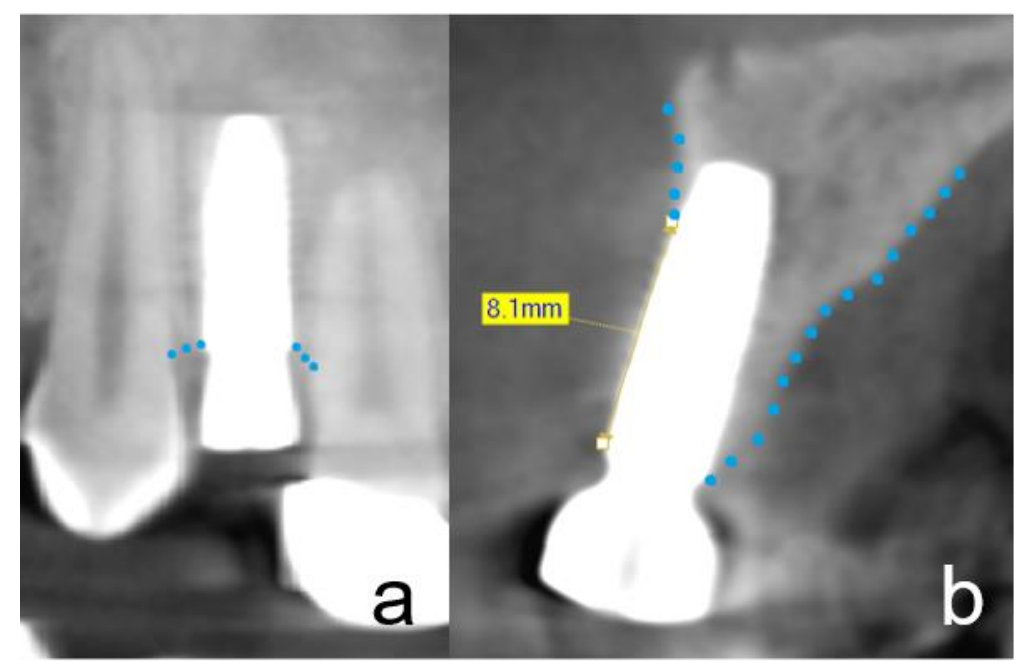

Figure 3. CBCTs after implant exposure. Dotted lines trace the outline of the alveolar ridge. (a) No horizontal bone loss at the mesial and distal implant shoulder is detectable at the time of implant exposure. (b) Measurement at the time of implant exposure from the implant shoulder to the first implant/hard tissue bone contact. In this case, $8.1 \mathrm{~mm}$ of the buccal lamella bone was completely resorbed.

All measurements were performed with the Ez3D Plus software (Vatech Co. Ltd., Hwaseong-si, Korea) by one previously calibrated investigator.

\subsection{Osseointegration}

Complete osseointegration was defined as:

- A peri-implant bone loss less than $1 \mathrm{~mm}$ at the four measuring points;

- $\quad$ An ISQ value over 60;

- A implant covered by a radio-opaque structure in CBCT;

- The integrity of the buccal lamella being preserved in the CBCT (no more than $1 \mathrm{~mm}$ loss).

\subsection{Prosthetic Restoration}

The prosthetic restoration began 4 weeks after implant exposure. After a further 4 weeks, the dentures were incorporated, so that the treatment was completed after a total of 5 months.

\subsection{Statistical Analyses}

Data were compiled in Excel and analyzed with IBM SPSS Statistics 22 (SPSS Inc., Chicago, IL, USA) in Windows 7. All the evaluations were computed at the patient, region, and implant level.

Mean values and standard deviations at times $\mathrm{T} 1$ and $\mathrm{T} 2$ were calculated for buccopalatal alveolar ridge width (L2) and buccal lamella width (L0, L2, and L4). The difference between $\mathrm{T} 1$ and $\mathrm{T} 2$ at the different levels $\mathrm{L}_{\mathrm{x}}$ was calculated to evaluate the resorption of the buccal lamella. The resorption of the alveolar crest width was calculated at L2.

The statistical methods included cross-tabulations with Fisher's exact tests for categorical data. Mean values were compared by two-sample $t$-tests.

A probability of error of $p<0.05$ was interpreted as significant.

\section{Results}

In the period from 1 June 2019 to 31 March 2020, the TST was carried out in 34 patients (19 female, 15 male) in 40 regions (Tables 1 and 2). The mean age of the patients at the time of implant placement was 61.7 years. There was no difference in gender and age distribution in the groups. A total of 45 implants were placed simultaneously with the TST. The ASTRA TECH Implant System ${ }^{\mathrm{TM}}$ EV (Astra Tech Implant System, Dentsply 
Sirona, York, PA, USA), Nobel Biocare (Nobel Biocare, Kloten, Switzerland) and Conelog $\left(\mathrm{CONELOG}^{\circledR}\right.$, ALTATEC GmbH, Wimsheim, Germany) were used as implant systems.

Table 1. Baseline characteristics of the participating patients at the time of augmentation procedure with autogenous dentin.

\begin{tabular}{ccccc}
\hline & & \multicolumn{2}{c}{ Study Group } & Sign \\
\hline Baseline Data of Participants & Total & ETT & NETT & -Value \\
\hline Age (years) & & & & \\
Mean (SD) & $61.7(10.5)$ & $62.6(8.6)$ & $60.8(12.4)$ & n.s. \\
Range & $28-80$ & $49-80$ & $28-76$ & \\
Gender (male) & & & & \\
$n(\%)$ & 15 of $34(44)$ & 6 of $17(35)$ & 9 of $17(52)$ & n.s. \\
\hline
\end{tabular}

ETT: Endodontically treated teeth; NETT: Non-endodontically treated teeth.

Table 2. Clinical complications at the patient, region, and implant level.

\begin{tabular}{|c|c|c|c|c|}
\hline \multirow[b]{2}{*}{ Clinical Complication } & \multirow[b]{2}{*}{ Total } & \multicolumn{2}{|c|}{ Study Group } & \multirow{2}{*}{$\begin{array}{c}\text { Fisher's Exact Test (2-Sided) } \\
p \text {-Value }\end{array}$} \\
\hline & & ETT & NETT & \\
\hline \multicolumn{5}{|l|}{ Total severe complications } \\
\hline$n(\%)$ on PL & 0 of $34(0)$ & 0 of $17(0)$ & 0 of $17(0)$ & n.s. \\
\hline$n(\%)$ on RL & 0 of $40(0)$ & 0 of $18(0)$ & 0 of $22(0)$ & n.s. \\
\hline$n(\%)$ on IL & 0 of $45(0)$ & 0 of $21(0)$ & 0 of $24(0)$ & n.s. \\
\hline \multicolumn{5}{|l|}{ Wound dehiscence } \\
\hline$n(\%)$ on PL & 2 of $34(6)$ & 1 of $17(6)$ & 1 of $17(6)$ & 1.000 \\
\hline$n(\%)$ on $\mathrm{RL}$ & 2 of $40(8)$ & 1 of $18(6)$ & 1 of $22(5)$ & 0.884 \\
\hline$n(\%)$ on IL & 2 of $45(4)$ & 1 of 21 (5) & 1 of $24(4)$ & 0.923 \\
\hline \multicolumn{5}{|l|}{ Inflammation (pus) } \\
\hline$n(\%)$ on PL & 0 of $34(0)$ & 0 of $17(0)$ & 0 of $17(0)$ & n.s. \\
\hline$n(\%)$ on $\mathrm{RL}$ & 0 of $40(0)$ & 0 of $18(0)$ & 0 of $22(0)$ & n.s. \\
\hline$n(\%)$ on IL & 0 of $45(0)$ & 0 of $21(0)$ & 0 of $24(0)$ & n.s. \\
\hline \multicolumn{5}{|l|}{ Total complications at all } \\
\hline$n(\%)$ on PL & 3 of $34(9)$ & 1 of $17(6)$ & 2 of $17(12)$ & 0.545 \\
\hline$n(\%)$ on $\mathrm{RL}$ & 3 of $40(8)$ & 1 of $18(6)$ & 2 of $22(9)$ & 0.673 \\
\hline$n(\%)$ on IL & 3 of $45(9)$ & 1 of $21(5)$ & 2 of $24(8)$ & 0.632 \\
\hline
\end{tabular}

ETT: Endodontically treated teeth; NETT: Non-endodontically treated teeth; PL: Patient level; RL: Region level; IL: Implant level.

\subsection{Severe Clinical Complications}

During the whole follow-up period, no severe complication occurred (Table 2).

\subsection{Non-Severe Clinical Complications}

During the whole follow-up period, there were three non-severe complications (Table 2). One dehiscence occurred in each of the two study groups. One case in the NETT group exhibited a localized three-walled defect of $5 \mathrm{~mm}$.

\subsection{Radiographic Evaluation}

At $\mathrm{T} 1$ and T2, evaluation of the CBCT images showed no cases with bone loss at the mesial or distal implant shoulder. Additionally, there was no vertical loss of the buccal lamella (Figure $4 \mathrm{a}-\mathrm{d}$ ). All the implants were completely covered with hard tissue. 


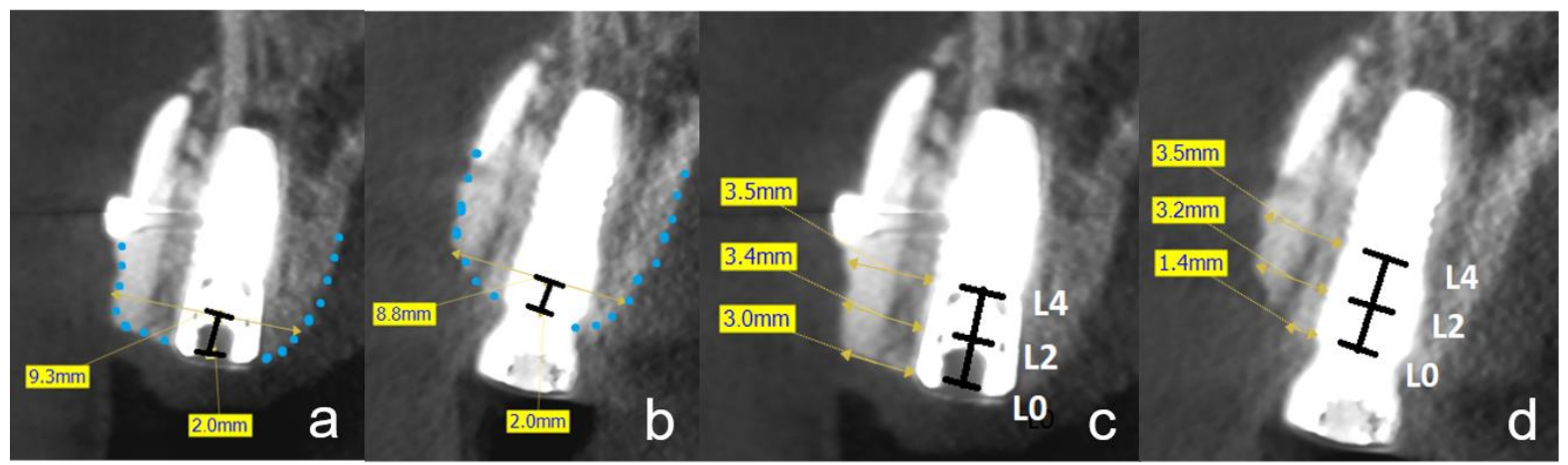

Figure 4. CBCTs after lateral ridge augmentation with simultaneous implantation and after implant exposure. (a) A CBCT in the sagittal plane shows an implant region 12 with TST at the time of lateral ridge augmentation. The buccal tooth shell is clearly visible. Dotted lines trace the outline of the alveolar ridge. The measurement of the bucco-oral alveolar ridge width was performed at level L2. In this case, the ridge width was $9.3 \mathrm{~mm}$. (b) The same procedure of the measurement of the bucco-oral alveolar ridge width was performed at the time of implant exposure. The tooth shell shows some resorption only at L0. (c) Measurements of the thickness of the buccal bone lamella at three different levels (L0, L2, and L4) at the time of lateral ridge augmentation. (d) Measurements of the thickness of the buccal bone lamella at three different levels (L0, L2, and L4) at the time of implant exposure.

All the measurements of the alveolar ridge width and resorption of the buccal lamella on the implants are summarized in Tables 3 and 4 (measurement sites as shown in Figure $3 a, b$ ). The alveolar ridge width (at the patient level) at the time of bone graft was, on average, $9.3 \mathrm{~mm}$ for ETT and $8.7 \mathrm{~mm}$ for NETT at level L2. At the time of follow-up (3 months after augmentation), the alveolar ridge width was $9 \mathrm{~mm}$ for ETT and $8.2 \mathrm{~mm}$ for NETT at level L2. This means the resorption was $0.3 \mathrm{~mm}$ for ETT and $0.5 \mathrm{~mm}$ for NETT on average (Table 4). At time T2, the mean buccal lamella width at L4 was significantly lower for NETT than for ETT at the implant, region, and patient level.

Table 3. Mean alveolar ridge bone measurements directly after grafting (T1) and at time of follow up (T2).

\begin{tabular}{|c|c|c|c|c|}
\hline \multirow[b]{2}{*}{ Time of Measurement } & \multirow[b]{2}{*}{ Mean } & \multicolumn{2}{|c|}{ Study Group } & \multirow{2}{*}{$\frac{\text { Two-Sample } t \text {-Test }}{(p \text {-Value })}$} \\
\hline & & ETT & NETT & \\
\hline \multicolumn{5}{|c|}{$\mathrm{T} 1$} \\
\hline \multicolumn{5}{|c|}{ Mean bucco-palatal alveolar ridge width (mm) } \\
\hline PL, $n=34(\mathrm{SD})$ & $9.1(1.5)$ & $9.4(1.7)$ & $8.7(1.2)$ & 0.146 \\
\hline $\mathrm{RL}, n=40$ (SD) & $9.0(1.5)$ & $9.3(1.8)$ & $8.7(1.1)$ & 0.205 \\
\hline $\mathrm{IL}, n=45(\mathrm{SD})$ & $9.0(1.5)$ & $9.3(1.8)$ & $8.8(1.3)$ & 0.229 \\
\hline \multicolumn{5}{|c|}{ Mean buccal lamella width L0 (mm) } \\
\hline $\mathrm{PL}, n=34(\mathrm{SD})$ & $2.7(0.9)$ & $2.6(1.0)$ & $2.7(0.8)$ & 0.917 \\
\hline $\mathrm{RL}, n=40$ (SD) & $2.6(0.9)$ & $2.6(1.0)$ & $2.7(0.8)$ & 0.742 \\
\hline $\mathrm{IL}, n=45(\mathrm{SD})$ & $2.6(0.9)$ & $2.6(1.0)$ & $2.7(0.9)$ & 0.702 \\
\hline \multicolumn{5}{|c|}{ Mean buccal lamella width L2 (mm) } \\
\hline PL, $n=34(\mathrm{SD})$ & $3.2(0.9)$ & $3.4(1.0)$ & $3.0(0.8)$ & 0.187 \\
\hline $\mathrm{RL}, n=40$ (SD) & $3.1(0.9)$ & $3.3(1.1)$ & $3.0(0.8)$ & 0.314 \\
\hline $\mathrm{IL}, \mathrm{n}=45(\mathrm{SD})$ & $3.2(0.9)$ & $3.3(1.0)$ & $3.0(0.8)$ & 0.391 \\
\hline \multicolumn{5}{|c|}{ Mean buccal lamella width L4 (mm) } \\
\hline PL, $n=34(\mathrm{SD})$ & $3.5(1.3)$ & $3.9(1.5)$ & $3.1(1.0)$ & 0.079 \\
\hline $\mathrm{RL}, n=40$ (SD) & $3.4(0.9)$ & $3.8(1.5)$ & $3.1(1.0)$ & 0.096 \\
\hline $\mathrm{IL}, n=45(\mathrm{SD})$ & $3.4(1.3)$ & $3.8(1.5)$ & $3.2(1.1)$ & 0.118 \\
\hline \multicolumn{5}{|c|}{$\mathrm{T} 2$} \\
\hline \multicolumn{5}{|c|}{ Mean bucco-palatal alveolar ridge width ( $\mathrm{mm})$} \\
\hline PL, $n=34(\mathrm{SD})$ & $8.7(1.4)$ & $9.1(1.7)$ & $8.2(1.0)$ & 0.073 \\
\hline $\mathrm{RL}, n=40$ (SD) & $8.6(1.4)$ & $9.0(1.7)$ & $8.2(1.0)$ & 0.101 \\
\hline $\mathrm{IL}, n=45(\mathrm{SD})$ & $8.6(1.4)$ & $9.0(1.7)$ & $8.3(1.0)$ & 0.077 \\
\hline
\end{tabular}


Table 3. Cont.

\begin{tabular}{|c|c|c|c|c|}
\hline \multirow[b]{2}{*}{ Time of Measurement } & \multirow[b]{2}{*}{ Mean } & \multicolumn{2}{|c|}{ Study Group } & \multirow{2}{*}{$\begin{array}{c}\text { Two-Sample } t \text {-Test } \\
(p \text {-Value })\end{array}$} \\
\hline & & ETT & NETT & \\
\hline \multicolumn{5}{|c|}{ Mean buccal lamella width L0 (mm) } \\
\hline PL, $n=34(\mathrm{SD})$ & $2.2(1.0)$ & $2.2(1.1)$ & $2.2(0.9)$ & 0.904 \\
\hline $\mathrm{RL}, n=40$ (SD) & $2.2(1.0)$ & $2.2(1.0)$ & $2.1(0.9)$ & 0.810 \\
\hline $\mathrm{IL}, n=45(\mathrm{SD})$ & $2.2(1.0)$ & $2.3(1)$ & $2.2(0.9)$ & 0.798 \\
\hline \multicolumn{5}{|c|}{ Mean buccal lamella width L2 (mm) } \\
\hline $\mathrm{PL}, n=34(\mathrm{SD})$ & $3.0(1.0)$ & $3.2(1.0)$ & $2.7(0.8)$ & 0.093 \\
\hline $\mathrm{RL}, n=40$ (SD) & $2.9(1.0)$ & $3.2(1.0)$ & $2.6(0.9)$ & 0.093 \\
\hline $\mathrm{IL}, n=45(\mathrm{SD})$ & $2.9(1.0)$ & $3.2(1.0)$ & $2.7(0.9)$ & 0.093 \\
\hline \multicolumn{5}{|c|}{ Mean buccal lamella width L4 (mm) } \\
\hline $\mathrm{PL}, n=34(\mathrm{SD})$ & $3.2(1.3)$ & $3.7(1.4)$ & $2.8(1.0)$ & 0.029 \\
\hline $\mathrm{RL}, n=40$ (SD) & $3.2(1.3)$ & $3.6(1.5)$ & $2.8(1.0)$ & 0.038 \\
\hline $\mathrm{IL}, n=45(\mathrm{SD})$ & $3.2(1.3)$ & $3.6(1.4)$ & $2.8(1.0)$ & 0.035 \\
\hline
\end{tabular}

N: Number; SD: Standard deviation; ETT: Endodontically treated teeth; NETT: Non-endodontically treated teeth; PL: Patient level; RL: Region level; IL: Implant level.

Table 4. Mean resorption of bucco-oral alveolar ridge bone width and buccal lamella bone plate from $\mathrm{T} 1$ to $\mathrm{T} 2$.

\begin{tabular}{ccccc}
\hline & & \multicolumn{2}{c}{ Study Group } & $\begin{array}{c}\text { Two-Sample } \\
t \text {-Test }\end{array}$ \\
\hline Mean Resorption in mm & Mean & ETT & NETT & ( $\boldsymbol{p}$-Value) \\
\hline bucco-oral alveolar ridge & & & \\
PL, $n=34$ (SD) & $0.39(0.68)$ & $0.34(0.35)$ & $0.45(0.90)$ & 0.637 \\
RL, $n=40$ (SD) & $0.40(0.66)$ & $0.33(0.36)$ & $0.45(0.83)$ & 0.551 \\
IL, $n=45$ (SD) & $0.40(0.67)$ & $0.30(0.35)$ & $0.49(0.85)$ & 0.340 \\
L0 & & & \\
PL, $n=34$ (SD) & $0.45(0.72)$ & $0.41(0.68)$ & $0.49(0.77)$ & 0.770 \\
RL, $n=40$ (SD) & $0.47(0.72)$ & $0.38(0.68)$ & $0.54(0.75)$ & 0.467 \\
IL, $n=45$ (SD) & $0.42(0.70)$ & $0.33(0.64)$ & $0.51(0.76)$ & 0.398 \\
L2 & & & \\
PL, $n=34$ (SD) & $0.24(0.56)$ & $0.17(0.43)$ & $0.31(0.68)$ & 0.483 \\
RL, $n=40$ (SD) & $0.26(0.58)$ & $0.14(0.44)$ & $0.36(0.67)$ & 0.247 \\
IL, $n=45$ (SD) & $0.25(0.55)$ & $0.12(0.41)$ & $0.36(0.64)$ & 0.149 \\
L4 & & & \\
PL, $n=34$ (SD) & $0.28(0.61)$ & $0.19(0.55)$ & $0.37(0.69)$ & 0.416 \\
RL, $n=40$ (SD) & $0.26(0.60)$ & $0.18(0.54)$ & $0.32(0.65)$ & 0.473 \\
IL, $n=45$ (SD) & $0.26(0.58)$ & $0.16(0.50)$ & $0.34(0.63)$ & 0.302 \\
\hline
\end{tabular}

N: Number; SD: Standard deviation; ETT: Endodontically treated teeth; NETT: Non-endodontically treated teeth; PL: Patient level; RL: Region level; IL: Implant level.

The mean thickness (at the patient level) of the buccal lamella was, at the time of bone graft T1/L0, $2.6 \mathrm{~mm}$ in the ETT group and $2.7 \mathrm{~mm}$ in the NETT group; at T1/L2, $3.4 \mathrm{~mm}$ for ETT and $3.0 \mathrm{~mm}$ for NETT; and at T1/L4, $3.9 \mathrm{~mm}$ for ETT and $3.1 \mathrm{~mm}$ for NETT; and at the time of follow-up T2/L0, $2.2 \mathrm{~mm}$ in ETT and $2.2 \mathrm{~mm}$ in NETT; at T2/L2, $3.2 \mathrm{~mm}$ in ETT and $2.7 \mathrm{~mm}$ in NETT; and at T2/L4, $3.7 \mathrm{~mm}$ in ETT and $2.8 \mathrm{~mm}$ in NETT. The resorption of the buccal lamella was, at T1-2/L0, $0.4 \mathrm{~mm}$ in ETT and $0.5 \mathrm{~mm}$ in NETT; at T1-2/L2, $0.2 \mathrm{~mm}$ in ETT and $0.3 \mathrm{~mm}$ in NETT; and at T1-2/L4, $0.2 \mathrm{~mm}$ in ETT and $0.3 \mathrm{~mm}$ in NETT (Table 4). Since $0.3 \mathrm{~mm}$ in ETT and $0.5 \mathrm{~mm}$ in NETT resorption of the alveolar ridge width occurred in T1-2/L2, the oral lamella must also have resorption of $0.1 \mathrm{~mm}$ ETT and $0.2 \mathrm{~mm}$ in NETT. In all cases with TST, the dentin shell was clearly visible.

The ratio of the bucco-oral alveolar crest width (at patient level) between T1 and T2 was 0.97 for ETT and 0.96 for NETT. For the thickness buccal lamella the ratio between T1 and T2 was at L0 0.85 for ETT and 0.84 for NETT, at L2 0.96 for ETT and 0.91 for NETT and at L4 0.97 for ETT and 0.90 for NETT (Table 5). 
Table 5. Ratio of residual ridge width of bucco-oral alveolar ridge and buccal lamella from T1 to T2.

\begin{tabular}{ccccc}
\hline & & \multicolumn{2}{c}{ Study Group } & $\begin{array}{c}\text { Two-Sample } \\
t \text {-Test }\end{array}$ \\
\hline Ratio from T1 to T2 & Mean & ETT & NETT & ( -Value) \\
\hline bucco-oral alveolar ridge & & & \\
PL, $n=34$ (SD) & $0.96(0.08)$ & $0.97(0.04)$ & $0.96(0.10)$ & 0.680 \\
RL, $n=40$ (SD) & $0.96(0.07)$ & $0.97(0.04)$ & $0.95(0.09)$ & 0.568 \\
IL, $n=45$ (SD) & $0.96(0.07)$ & $0.97(0.04)$ & $0.95(0.09)$ & 0.402 \\
L0 & & & \\
PL, $n=34$ (SD) & $0.85(0.29)$ & $0.85(0.26)$ & $0.84(0.33)$ & 0.917 \\
RL, $n=40$ (SD) & $0.84(0.29)$ & $0.87(0.26)$ & $0.81(0.31)$ & 0.521 \\
IL, $n=45$ (SD) & $0.86(0.30)$ & $0.88(0.25)$ & $0.84(0.34)$ & 0.588 \\
L2 & & & \\
PL, $n=34$ (SD) & $0.93(0.18)$ & $0.96(0.13)$ & $0.91(0.22)$ & 0.457 \\
RL, $n=40$ (SD) & $0.93(0.19)$ & $0.97(0.15)$ & $0.89(0.22)$ & 0.199 \\
IL, $n=45$ (SD) & $0.93(0.18)$ & $0.98(0.14)$ & $0.89(0.21)$ & 0.125 \\
L4 & & & \\
PL, $n=34$ (SD) & $0.93(0.19)$ & $0.97(0.17)$ & $0.90(0.20)$ & 0.286 \\
RL, $n=40$ (SD) & $0.94(0.19)$ & $0.97(0.17)$ & $0.91(0.20)$ & 0.363 \\
IL, $n=45$ (SD) & $0.94(0.18)$ & $0.97(0.16)$ & $0.91(0.19)$ & 0.239 \\
\hline
\end{tabular}

N: Number; SD: Standard deviation; ETT: Endodontically treated teeth; NETT: Non-endodontically treated teeth; PL: Patient level; RL: Region level; IL: Implant level.

\subsection{Peri-Implant Tissue Probing}

With one exception, the probing depth did not exceed $0.5 \mathrm{~mm}$. This case is the aforementioned complication, with a three-walled local bone defect of $5 \mathrm{~mm}$.

\subsection{Implant Stability}

The ISQ value was over 60 for all the implants and was in the range of $61-88$. The mean ISQ value for the ETT group was 74 and for NETT group 75. There were no significant differences between the groups.

\subsection{Osseointegration}

Since there was no increased probing depth, except for one case in which augmentation was carried out afterwards, the ISQ values were over 60 , and all the implant surfaces were covered with hard tissue. All the implants were, by definition, completely osseointegrated.

\subsection{Prosthetic Restoration}

All the implants could be prosthetically restored with a fixed denture. No complications occurred with any of the implants in the period between implant exposure and final prosthetic restoration, except for the one case in which a re-augmentation was performed. This implant could be restored with a fixed denture, 3 months later.

\section{Discussion}

The aim of the present retrospective study was to assess the feasibility of using reconditioned dentin from endodontically treated teeth for lateral ridge augmentation by means of the tooth shell technique. A total of 34 patients, in which the grafting procedures according to the TST (endodontically and non-endodontically treated teeth) with simultaneous implant placement were performed, were followed up with focus on clinical complications and short-term dimensional changes of the crestal width and the buccal lamella.

One of the major concerns of using reconditioned dentin from endodontically treated teeth for grafting procedures was the potential risk of compromised healing with premature graft exposure or even the loss of the graft and/or the implant due to inflammatory processes which increases the patient's impairments by discomfort or necessary second 
interventions. This would be in contrast with the advantage of the considerably lower invasiveness of the tooth shell technique compared to autogenous bone block grafts.

The low incidence of non-severe clinical complications observed in our study $(n=3)$ is comparable with the results reported for autogenous bone grafts [3]. Soft tissue dehiscence with partial graft exposure occurred on two grafted sites (NETT $n=1$; ETT $n=1$ ) during the early recovery stage. At re-entry after 3 months, one implant in the NETT group exhibited a localized three-walled defect, which could be solved by re-augmentation. Severe complications such as loss of implant or massive resorption of the graft were not observed. The noted incidence of clinical complications corresponds to those reported in previous studies on this technique and bone shell technique [22,31].

Preclinical animal studies have revealed slightly higher graft exposure rates for endodontically treated teeth compared to uncompromised teeth [20]. In the present study, this could not be observed. However, these grafts were only mechanically processed and not subjected to decontamination. The dentin preparation and decontamination procedure used in the present study is a commercially available method for preparing particulate dentin for grafting procedures, using sodium hydroxide in a $0.5 \mathrm{M}$ solution and $70 \%$ ethanol for cleansing. However, there is a lack of basic research data regarding the bactericidal efficacy of this method, especially against bacterial infections in endodontic niches such as dentinal tubules. A potential drawback of these decontamination procedures is their possible adverse effect on biological properties. The effectiveness of sodium hydroxide as a disinfectant, for example, is based primarily on its ability to cleave protein bonds and disintegrate the tertiary structure of proteins. This denaturation of proteins may hypothetically also affect structural proteins of the organic matrix and osteoinductive growth factors such as BMPs, IGF-II, and TGF-B. Thermal treatment such as autoclavation as an alternative for the decontamination of the dentin material prior to grafting may also result in protein denaturation. A preclinical animal study reported a significant decreased level of osseointegration (bone-implant contact) if the dentin was pretreated by autoclavation compared to untreated dentin [18]. In contrast, other animal models provided some evidence that in autoclaved dentin matrix dental pulp stem cells were preserved and kept the capability to promote new tissue formation [32].

Since the present study was a clinical study, there was no possibility to analyze boneimplant contact as a measure for osseointegration. In this study, osseointegration was evaluated by the resonance frequency analysis, as well as the clinical and radiographic evaluation of the hard tissues covering the implant. The resonance frequency analysis is a reproducible and validated method for assessing the implant stability quotient (ISQ) as a surrogate parameter for osseointegration [33,34]. By definition, implants with an ISQ level exceeding 60 are considered to be sufficiently stable for being loaded. The high levels of implant stability (ISQ) observed in both groups (NETT: 75, ETT: 74) suggest a sufficient and equivalent level of osseointegration, which were comparable with the ISQ levels of implants placed simultaneously with the bone shell technique according to Khoury [31]. This is underlined by the clinical finding that, except for one case, no vertical peri-implant bone loss exceeding $0.5 \mathrm{~mm}$ could be detected.

Traditionally, the radiographic analysis of osseointegration and crestal bone level is performed by two-dimensional radiographs [35]. This allows the assessment of the peri-implant bone level in the approximal aspect, but not of the bucco-oral dimension, in particular the buccal lamella which consists of grafted hard tissue only. In the present study, the radiographic evaluation was therefore performed by small-volume CBCT scans after augmentation and at re-entry after 3 months for implant exposure. The peri-implant bone level measured in the mesial and distal aspect of the implant shoulder, did not reveal any vertical bone loss. At time T2, the mean buccal lamella width at L4 was significantly lower for NETT than for ETT at the implant, region, and patient level. However, these values only show the comparison of the widths at a certain point in time and not the resorption over time. The mean resorption of the bucco-oral dimension of alveolar crest width between grafting and re-entry at 3 months amounted to $0.3 \mathrm{~mm}$ in the EET group and $0.5 \mathrm{~mm}$ in the 
NETT group and did not show any significant differences between the two groups. The major part of the resorption can be found with $0.2 \mathrm{~mm}$ in the ETT and $0.3 \mathrm{~mm}$ at the buccal lamella. However, at $30-40 \%$ of the dimensional change, a not inconsiderable proportion of this is accounted for the oral lamella, i.e., the native bone. The mean resorption of the buccal plate noted in this study suggests the stability of the dentin graft in the short-term aspect and underlines the findings that dentin grafts show a less pronounced resorption compared to bone [20]. This evaluation is limited by a relatively short observation period of 3 months. The effect of graft and bone remodeling on long-term dimensional changes needs to be addressed in future studies.

A further limitation of this study is the lack of histological investigation. As grafting with the simultaneous implant placement was performed in the present study, no biopsies (e.g., bone cores in context of implant bed preparation) could be obtained. An additional biopsy was not considered due to ethical concerns. Based on CBCT data, it is not possible to determine whether the dentin shell and particulate has been remodeled by osseous replacement or if unaltered dentin is present, especially since the dentin shell remains clearly delineable. However, there is histological evidence that dentin undergoes gradual replacement resorption and promotes new bone formation [14,16,23,36,37].

It has been proven that autogenous dentin is a safe alternative to autogenous bone for the lateral alveolar ridge, providing predictable grafting results. The tooth shell technique that was applied in the present study was able to broaden the spectrum of indications, as a larger volume can be augmented than with a solid tooth root and simultaneous implant placement can be performed [22]. The feasibility of using reconditioned dentin from endodontically treated teeth for this application is a further advantage since root fractures of endodontically treated teeth represent a common reason for tooth extraction and alveolar bone defects.

\section{Conclusions}

Within its limitations, this retrospective study was able to show that the use of reconditioned dentin from endodontically treated teeth for grafting procedures according to the tooth shell technique leads to results equivalent to those for non-endodontically treated teeth. The possible use of reconditioned dentin from endodontically treated teeth for the TST broadens the scope of the application of this technique.

Author Contributions: Conceptualization, M.K. and M.P.; methodology, M.K. and M.P.; software, M.K.; validation, M.K.; formal analysis, M.K. and M.P.; investigation, M.K.; resources, M.K.; data curation, M.K.; writing — original draft preparation, M.K. and M.P.; visualization, M.K.; supervision, M.K.; project administration, M.K. Both authors have read and agreed to the published version of the manuscript.

Funding: This research received no external funding.

Institutional Review Board Statement: The authors declare that the investigations were carried out following the rules of the Declaration of Helsinki of 1964 (https:/ / www.wma.net/what-wedo/medical-ethics/declaration-of-helsinki/) (June 1964), revised in 2013. The Ethics Committee of the Institutional Review Board of the Baden-Württemberg Medical Board reviewed and approved the proposed study (ID: F-2020-068-z) (6 May 2020). Probands were not part of the study. It was a retrospective study with data collection and anonymous data processing.

Informed Consent Statement: The Ethics Committee decided that patients whose data were collected did not need to be informed.

Data Availability Statement: Data are contained within the article.

Acknowledgments: The authors would like to thank Shems Alamer for excellent data acquisition.

Conflicts of Interest: The authors declare no conflict of interest. 


\section{References}

1. Sakkas, A.; Wilde, F.; Heufelder, M.; Winter, K.; Schramm, A. Autogenous bone grafts in oral implantology-Is it still a "gold standard"? A consecutive review of 279 patients with 456 clinical procedures. Int. J. Implant. Dent. 2017, 3, 23. [CrossRef]

2. Nkenke, E.; Radespiel-Troger, M.; Wiltfang, J.; Schultze-Mosgau, S.; Winkler, G.; Neukam, F.W. Morbidity of harvesting of retromolar bone grafts: A prospective study. Clin. Oral Implant. Res. 2002, 13, 514-521. [CrossRef]

3. Sakkas, A.; Schramm, A.; Winter, K.; Wilde, F. Risk factors for post-operative complications after procedures for autologous bone augmentation from different donor sites. J. Craniomaxillofac. Surg. 2018, 46, 312-322. [CrossRef]

4. Kim, Y.K.; Lee, J.; Um, I.W.; Kim, K.W.; Murata, M.; Akazawa, T.; Mitsugi, M. Tooth-derived bone graft material. J. Korean Assoc. Oral Maxillofac. Surg. 2013, 39, 103-111. [CrossRef] [PubMed]

5. Murata, M.; Akazawa, T.; Mitsugi, M.; Kabir, M.A.; Um, I.W.; Minamida, Y.; Kim, K.-W.; Kim, Y.-K.; Sun, Y.; Qin, Y.S.A.C. Autograft of Dentin Materials for Bone Regeneration. IntechOpen 2013, 2013, 391-402.

6. Al-Asfour, A.; Andersson, L.; Kamal, M.; Joseph, B. New bone formation around xenogenic dentin grafts to rabbit tibia marrow. Dent. Traumatol. 2013, 29, 455-460. [CrossRef]

7. Al-Asfour, A.; Farzad, P.; Al-Musawi, A.; Dahlin, C.; Andersson, L. Demineralized Xenogenic Dentin and Autogenous Bone as Onlay Grafts to Rabbit Tibia. Implant. Dent. 2017, 26, 232-237. [CrossRef]

8. Andersson, L. Dentin xenografts to experimental bone defects in rabbit tibia are ankylosed and undergo osseous replacement. Dent. Traumatol. 2010, 26, 398-402. [CrossRef]

9. Bono, N.; Tarsini, P.; Candiani, G. Demineralized dentin and enamel matrices as suitable substrates for bone regeneration. J. Appl. Biomater. Funct. Mater. 2017, 15, e236-e243. [CrossRef]

10. Bormann, K.H.; Suarez-Cunqueiro, M.M.; Sinikovic, B.; Kampmann, A.; von See, C.; Tavassol, F.; Binger, T.; Winkler, M.; Gellrich, N.-C.; Rücker, M. Dentin as a suitable bone substitute comparable to ss-TCP-an experimental study in mice. Microvasc. Res. 2012, 84, 116-122. [CrossRef]

11. Jun, S.H.; Ahn, J.S.; Lee, J.I.; Ahn, K.J.; Yun, P.Y.; Kim, Y.K. A prospective study on the effectiveness of newly developed autogenous tooth bone graft material for sinus bone graft procedure. J. Adv. Prosthodont. 2014, 6, 528-538. [CrossRef] [PubMed]

12. Kim, S.Y.; Kim, Y.K.; Park, Y.H.; Park, J.C.; Ku, J.K.; Um, I.W.; Kim, J.-Y. Evaluation of the Healing Potential of Demineralized Dentin Matrix Fixed with Recombinant Human Bone Morphogenetic Protein-2 in Bone Grafts. Materials 2017, 10, 1049. [CrossRef] [PubMed]

13. Kim, Y.K.; Yun, P.Y.; In-Woong Um, I.W.; Lee, H.J.; Yi, Y.J.; Bae, J.H.; Lee, J. Alveolar ridge preservation of an extraction socket using autogenous tooth bone graft material for implant site development: Prospective case series. J. Adv. Prosthodont. 2014, 6, 521-527. [CrossRef] [PubMed]

14. Schwarz, F.; Golubovic, V.; Becker, K.; Mihatovic, I. Extracted tooth roots used for lateral alveolar ridge augmentation: A proof-of-concept study. J. Clin. Periodontol. 2016, 43, 345-353. [CrossRef] [PubMed]

15. Schwarz, F.; Mihatovic, I.; Golubovic, V.; Becker, J. Dentointegration of a titanium implant: A case report. Oral Maxillofac. Surg. 2013, 17, 235-241. [CrossRef]

16. Cardaropoli, D.; Nevins, M.; Schupbach, P. New Bone Formation Using an Extracted Tooth as a Biomaterial: A Case Report with Histologic Evidence. Int. J. Periodontics Restor. Dent. 2019, 39, 157-163. [CrossRef]

17. Xu, X.; Sohn, D.S.; Kim, H.G.; Lee, S.J.; Moon, Y.S. Comparative Histomorphometric Analysis of Maxillary Sinus Augmentation With Deproteinized Bovine Bone and Demineralized Particulate Human Tooth Graft: An Experimental Study in Rabbits. Implant. Dent. 2018, 27, 324-331. [CrossRef]

18. Ramanauskaite, A.; Sahin, D.; Sader, R.; Becker, J.; Schwarz, F. Efficacy of autogenous teeth for the reconstruction of alveolar ridge deficiencies: A systematic review. Clin. Oral Investig. 2019, 23, 4263-4287. [CrossRef]

19. Parvini, P.; Sader, R.; Sahin, D.; Becker, J.; Schwarz, F. Radiographic outcomes following lateral alveolar ridge augmentation using autogenous tooth roots. Int. J. Implant. Dent. 2018, 4, 31. [CrossRef]

20. Schwarz, F.; Hazar, D.; Becker, K.; Sader, R.; Becker, J. Efficacy of autogenous tooth roots for lateral alveolar ridge augmentation and staged implant placement. A prospective controlled clinical study. J. Clin. Periodontol. 2018, 45, 996-1004. [CrossRef]

21. Li, P.; Zhu, H.; Huang, D. Autogenous DDM versus Bio-Oss granules in GBR for immediate implantation in periodontal postextraction sites: A prospective clinical study. Clin. Implant. Dent. Relat Res. 2018, 20, 923-928. [CrossRef]

22. Korsch, M. Tooth shell technique: A proof of concept with the use of autogenous dentin block grafts. Aust. Dent. J. 2020, 66, 159-168. [CrossRef] [PubMed]

23. Schwarz, F.; Golubovic, V.; Mihatovic, I.; Becker, J. Periodontally diseased tooth roots used for lateral alveolar ridge augmentation. A proof-of-concept study. J. Clin. Periodontol. 2016, 43, 797-803. [CrossRef] [PubMed]

24. Taschieri, S.; Del Fabbro, M.; Samaranayake, L.; Chang, J.W.; Corbella, S. Microbial invasion of dentinal tubules: A literature review and a new perspective. J. Investig. Clin. Dent. 2014, 5, 163-170. [CrossRef]

25. Siqueira, J.F., Jr.; Rôças, I.N. Diversity of endodontic microbiota revisited. J. Dent. Res. 2009, 88, 969-981. [CrossRef] [PubMed]

26. Kowalski, W.J.; Kasper, E.L.; Hatton, J.F.; Murray, B.E.; Nallapareddy, S.R.; Gillespie, M.J. Enterococcus faecalis adhesin, Ace, mediates attachment to particulate dentin. J. Endod. 2006, 32, 634-637. [CrossRef] [PubMed]

27. Love, R.M. Enterococcus faecalis-A mechanism for its role in endodontic failure. Int. Endod. J. 2001, 34, 399-405. [CrossRef]

28. Khoury, F.; Hanser, T. Three-Dimensional Vertical Alveolar Ridge Augmentation in the Posterior Maxilla: A 10-year Clinical Study. Int. J. Oral Maxillofac. Implant. 2019, 34, 471-480. [CrossRef] 
29. Korsch, M.; Kasprzyk, S.; Walther, W.; Bartols, A. Lateral alveolar ridge augmentation with autogenous block grafts fixed at a distance vs. resorbable poly-D-L-lactide foil fixed at a distance: 5-year results of a single-blind, randomised controlled trial. Int. J. Oral Implantol. 2019, 12, 299-312.

30. Bartols, A.; Kasprzyk, S.; Walther, W.; Korsch, M. Lateral alveolar ridge augmentation with autogenous block grafts fixed at a distance versus resorbable Poly-D-L-Lactide foil fixed at a distance: A single-blind, randomized, controlled trial. Clin. Oral Implant. Res. 2018, 29, 843-854. [CrossRef]

31. Korsch, M.; Peichl, M. Retrospective Study: Lateral Ridge Augmentation Using Autogenous Dentin: Tooth-Shell Technique vs. Bone-Shell Technique. Int. J. Environ. Res. Public Health 2021, 18, 3174. [CrossRef]

32. Chang, C.C.; Lin, T.A.; Wu, S.Y.; Lin, C.P.; Chang, H.H. Regeneration of Tooth with Allogenous, Autoclaved Treated Dentin Matrix with Dental Pulpal Stem Cells: An In Vivo Study. J. Endod. 2020, 46, 1256-1264. [CrossRef]

33. Kastel, I.; de Quincey, G.; Neugebauer, J.; Sader, R.; Gehrke, P. Does the manual insertion torque of smartpegs affect the outcome of implant stability quotients (ISQ) during resonance frequency analysis (RFA)? Int. J. Implant. Dent. 2019, 5, 42. [CrossRef] [PubMed]

34. Soares, P.B.; Moura, C.C.; Claudino, M.; Carvalho, V.F.; Rocha, F.S.; Zanetta-Barbosa, D. Influence of Implant Surfaces on Osseointegration: A Histomorphometric and Implant Stability Study in Rabbits. Braz. Dent. J. 2015, 26, 451-457. [CrossRef] [PubMed]

35. Gehrke, S.A.; Maté Sánchez de Val, J.E.; Ramírez Fernández, M.P.; Shibli, J.A.; Rossetti, P.H.; Calvo Guirado, J.L. Stability and Crestal Bone Behavior Following Simultaneous Placement of Multiple Dental Implants (Two or More) with the Bone Splitting Technique: A Clinical and Radiographic Evaluation. Clin. Implant. Dent. Relat Res. 2017, 19, 123-130. [CrossRef] [PubMed]

36. Becker, K.; Drescher, D.; Honscheid, R.; Golubovic, V.; Mihatovic, I.; Schwarz, F. Biomechanical, micro-computed tomographic and immunohistochemical analysis of early osseous integration at titanium implants placed following lateral ridge augmentation using extracted tooth roots. Clin. Oral Implant. Res. 2017, 28, 334-340. [CrossRef] [PubMed]

37. Qin, X.; Raj, R.M.; Liao, X.F.; Shi, W.; Ma, B.; Gong, S.Q.; Chen, W.-M.; Zhou, B. Using rigidly fixed autogenous tooth graft to repair bone defect: An animal model. Dent. Traumatol. 2014, 30, 380-384. [CrossRef] 